\title{
Developing Cooperative Project Client-Supplier Relationships: HOW MUCH TO EXPECT FROM Relational Contracts?
}

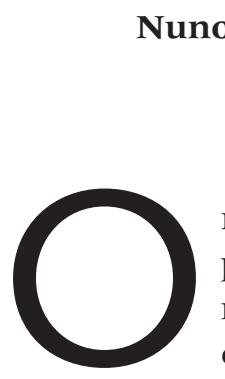

rganizations promoting new infrastructure projects range from private owners of airports, hospitals, and utilities to governments and local authorities. They typically chose to strategically position themselves as the project clients. Instead of

building in-house capabilities to design and build new infrastructure, they opt to intermittently source works from the fragmented architecture-engineering-construction supply chain. In the last decade, infrastructure promoters have become increasingly interested in translating the Toyota lean management paradigm-its underlying business infrastructure as well as technical processes-into the project environments associated with new infrastructure developments. ${ }^{1}$ A prerequisite at the core of this strategic approach is the development of cooperative relationships with the project suppliers. To enable this, infrastructure promoters realized they needed to rethink commercial practices and started to experiment with "relational" contracts. A relational contracting strategy-or "intertwined" strategy in that personal relations become heavily intertwined with the economic exchange ${ }^{2}$ - presumes that the project clients are willing to discard hard-nosed lump-sum forms of contracting for others that nurture cooperative, long-term relationships with the preferred project suppliers.

Through an in-depth empirical study on the implementation of relational contracts with all the first-tier suppliers involved in a large-scale infrastructure project, this article confirms the old adage that the devil is in the details. The empirical findings suggest that a relational contracting strategy undoubtedly enables the project client and suppliers to work together for a common purpose. However, the interwoven ways in which the client implements the strategy-in terms of, first, writing up the commercial details, and second, interpreting and adapting the contract design ex-post in the course of managing the project-are critical for encouraging the project suppliers to work cooperatively and meet the 
expectations of the client. This article inductively unpacks key do's and don'ts for making this type of contract work effectively in large-scale infrasctructure projects.

\section{Relational Contracts and Projects}

From the perspective of relational contract theory, all contracts have a relational element in the sense that all economic exchanges happen in a relational context. ${ }^{3}$ At one end of the spectrum are the discrete contracts emphasizing completeness, planning, and precise and tight measurements of performance-they suit short-term transactions involving limited personal interaction. At the other end are the "relational" (or "intertwined") contracts emphasizing future cooperative behavior, reciprocity, and mutual dependencethey suit long-term transactions requiring flexibility to make adjustments over time. The adoption of relational exchanges in the services and manufacturing sectors has received significant attention from a range of literatures, including transaction cost economics (transactions of the middle range), ${ }^{4}$ sociological approaches (neo-liberal forms of governance), ${ }^{5}$ and supply chain management (Japanese-style partnerships). ${ }^{6}$ The three strands of research share a common interest in finding sets of conditions and incentives that can drive independent firms to perform well and behave in a trustworthy manner throughout a relational transaction. Notwithstanding controversy, these literatures taken together elucidate how three elements—governance structures (legal contracts, business infrastructure); social forces (reputation, trust, history of the exchange, continuity); and reliability (stemming from agreed-

Nuno Gil is a Senior Lecturer (Associate Professor) at the Centre for Research in the Management of Projects (CRMP), Manchester Business School, The University of Manchester, UK. <nuno.gil@mbs.ac.uk> upon technical processes)—supplement one another in supporting cooperative inter-firm relationships and dissuading opportunistic behavior. Opportunism-the self-interest seeking of a strategic nature undertaken to redirect profits from vulnerable parties ${ }^{7}$ - would otherwise show through behaviors such as bargaining, failing to fulfill obligations, and withholding valuable information.

In contrast, our understanding of how these elements supplement each other for the same purpose in project environments, and particularly in largescale infrastructure projects, remains incipient. The uncertainty and ambiguity characterizing the requirements for these projects make the contracts between the clients and the suppliers necessarily incomplete. This problem is compounded by the fragmentation of the architecture-engineering-construction supply chains. ${ }^{8}$ By placing the highly interdependent design, manufacturing, and construction tasks under different authorities, these supply chains violate Stinchcombe's decoupling principle. ${ }^{9}$ This generates problems in information flow, decision making, biased communication, planning, and control. Sociological studies of applying a relational approach in projects to deliver the infrastructure for hosting the Sydney 2000 Olympic games have nonetheless suggested that relational contracts can minimize inter-firm conflict. Specifically, they can 
encourage project stakeholders to be contractually committed to develop a common culture, and to share a practical consciousness. ${ }^{10}$

The question at the core of this study builds upon this work, but it is more operational in nature. Whether buyer-supplier relationships succeed or fail is a function of the match between the governance structure and the characteristics of the relationships as much as it is of the extent to which the relationships are well or poorly managed. ${ }^{11}$ At the core of making the inter-firm relationships work well are the capabilities to contract with each other (how much and what kinds of detail to design into a contract) and to learn how to use the contracts once they are in place. ${ }^{12}$ Hence, this study asks: How can infrastructure promoters implement a relational contracting strategy so as to drive desired behaviors, given a history of adversarial relationships between project clients and suppliers? Can these contracts work with all the suppliers regardless of their capabilities and the nature of the work they do? Are there specific details that need to be designed into the contract to align ex-ante the parties' expectations and incentives? Which routines and practices can help to ensure an effective application of a relational contract in projects? Are these contracts resilient enough to help the client-supplier relationship cope with change requests as the project progresses from conception through design into construction?

\section{Research Base}

This article draws on the empirical findings of a $3 \frac{1}{2}$ year (2004-2007) embedded case study on the $£ 4.3$ bn (in 2007 prices) project to expand London's Heathrow Airport, the Terminal 5 (T5) project. ${ }^{13}$ The units of analysis are the inter-firm relationships between the project client, British Airports Authority (BAA), and the first-tier project suppliers. These relationships were framed commercially around a relational contract. The project scope encompassed a number of facilities to be delivered between 2002 and 2008, including terminal buildings, an air traffic control tower, aircraft stands, a baggage handling system, and an inter-terminal train. The contracting strategy aimed to encourage the suppliers to move away from "business as usual" to an environment where "we all continually challenge how we can be successful."

As with most large infrastructure projects, the assumptions that BAA knew what it wanted at the onset of the T5 project, and would continue to want the same thing overtime, were invalid. ${ }^{14}$ The contract-termed the T5 agreement-addressed the call that BAA made for suppliers to reduce production costs while remaining flexible to accommodate changes:

“The idea of building $£ 4$ bn worth of infrastructure over 4 or 5 years and not having to rework and go around the loop a couple of times is nonsensical. Therefore, we've to manage change and minimize it in the best way. We won't be able to get it right the first time. We need to be realistic; change is a fact of life." - T5 Project Lawyer

This study builds upon fieldwork involving almost 100 face-to-face interviews with: first, representatives of the project client, including project leaders, 
design and construction directors, the contract manager, and the T5 lawyer; and second, representatives of fifteen first-tier suppliers, including project directors and senior staff. While some T5 suppliers were unavailable to meet, or difficult to reach, the sample of suppliers that were interviewed illustrates their diversity in the sense it includes manufacturers, engineering design consultants, architectural practices, and contractors. When I started the fieldwork, the T5 agreement had been in use for more than 2 years and some commercial terms and conditions had been adjusted recently. This provided a unique opportunity to tap into the collective learning and experience about how to implement a relational contract effectively. I was not given access to quantitative data on costs and benchmarking exercises because it was deemed commercially sensitive. However, I was given unrestricted access to project participants, provided they agreed to make themselves available for a meeting. Armed with a phone directory for the project and awareness of the relevant theoretical constructs, I set off to systematically ask project participants for their views about the T5 agreement. Specifically, I asked about its suitability to enable-and encourage-inter-firm cooperative work, as well as key factors to get its implementation right under conditions of high uncertainty and ambiguity.

I triangulated interview data with the analysis of archival documents (contract documents, implementation plans, supplier assessment reports, and delivery strategies), with numerous informal conversations during the periods I was based at the site, and with data I gathered when attending presentations to select suppliers and workshops to disseminate the ethos of the T5 agreement. Admittedly, the qualitative data of the case study do not allow for statistical generalizations. However, scholarly work suggests that empirical studies grounded in managing an airport expansion project make up a fair representation of the challenges faced by managers of large-scale engineering projects. ${ }^{15}$ Accordingly, I believe this study sheds light on issues-and practices for offsetting their negative effects-that project managers want be aware of when applying a relational contracting strategy.

\section{The Journey of the Infrastructure Sector towards Relational Contracts: Theory and Practice}

Western legal philosophy assumes that formal contracts are an essential artifact mediating the relationship between distinct firms. Contracts represent obligations to perform particular actions in the future. The more potential hazards that the parties involved associate with those actions, the more they deem contracts necessary. ${ }^{16}$ Complex contracts detail the job roles and responsibilities, specify procedures for monitoring and penalties for nonconformance, and determine outcomes or outputs to be delivered. ${ }^{17}$ This view has been deeply rooted in the infrastructure sector. Project clients use contracts to wrap up the temporary relationships with the suppliers around a commercial framework. As Stinchcombe discerned, project clients use contracts to incorporate (or simulate) hierarchical elements in the project organization. They do so to certify with authority and legitimacy the flow of information and adjustments, placing the 
risk of being wrong with the person who instructs, not with the doer. ${ }^{18}$ However, because project conditions change over time, contractual authority and responsibility are constantly being created and destroyed, changed, reviewed, and even ignored to deal with emergencies.

Relational contract theory has indeed shown that contracts are, citing Oliver Williamson, a "good deal more varied and complex than is commonly realized." The theory sets out from the recognition that contracts concern cooperative social behavior where parties are willing and able to work with others. ${ }^{19}$ Further, it acknowledges that contracts are formulated both by the parties engaged in an economic exchange, as well as by the society and the law, and distinguishes between classical, neoclassical, and relational contracts. ${ }^{20}$

Classical contracts attempt to facilitate exchange by enhancing discreteness and completeness. They treat as irrelevant the identity of the parties and discourage third-party participation, relying instead on legal rules, formal documents, and self-liquidating transactions. Infrastructure promoters often adopt this approach, commissioning works to suppliers for lump-sums set at the start of the project through a competitive bidding process. In the UK, for example, the traditional contract forms such as the Joint Contracts Tribunal (JCT) and the Institution of Civil Engineers (ICE) embody this paradigm:

“These [JCT and ICE] are contracts in which parties take positions at the beginning as to what risks they'll take and then plan to react to them as they arrive. It's really about managing what happens after the event, and the contracts should say what parties are expected to do and what will happen if it all goes wrong."

- T5 Lawyer

More broadly, these contracts fit with Sako's category of arm's-length contracts. ${ }^{21}$ For the client to obtain competitive prices, these contracts are associated with hard bargaining, nonspecific asset investments, and minimal information sharing. They aim to sustain a low level of interdependence so as to guarantee low costs in switching suppliers. Yet, evidence shows that the contracts that rely on control and surveillance to check conformance are ineffective in large-scale infrastructure projects. ${ }^{22}$ As the T5 lawyer emphatically described:

“There's no point trying to think that the traditional contract-lots of indemnities, liquidated damages, penalties_-protects the client. I'm an ex-contractor. Many times clients asked me to work together, and then you get the contract, and it says 'stick one hair above the parapet and I'll fire at you.' What we have then is a behavioral response that says every time something goes wrong, the contractor will fire off a thousand letters explaining why it's not its fault."

In the face of the escalation of legal disputes in the eighties, infrastructure promoters started to incorporate alternative resolution techniques to resolve disputes into traditional contracts-a step change towards neoclassical contracts. ${ }^{23}$ This approach acknowledges that complete contracts are impossible to write (or prohibitively costly) for complex transactions such as many of those associated with large-scale infrastructure projects. This approach also recognizes that hard contracting invariably leads to disputes after suppliers make claims demanding compensation for additional work due to planning gaps, changes, 
and unexpected events. Hence, the neoclassical approach encourages planners to incorporate flexibility into the contracts, as well as provisions to use third-party assistance in resolving disputes and in evaluating performance, such as dispute review boards, mediation, and arbitration.

More recently, infrastructure promoters have begun to experiment with relational contracts. Inter-firm alliances between large, legally independent but economically interdependent firms are but one example of this type of contract. ${ }^{24}$ They involve substantial asset-specific investments, which cannot be easily measured or reallocated to other contracts without loss. Mutual interdependences and the prospects of getting repeated contracts as a function of reputation act as extra contractual protections. Parties become less vulnerable to holdups after making a specific investment because they could retaliate, notwithstanding the general contractual terms. These contracts suit situations-typical in infrastructure projects, not surprisingly-where parties would find it hard and costly to develop precise terms and conditions ex ante in anticipation of the way the exchange will unfold. Hence, the relational contracts acknowledge that mutual cooperation and flexibility are needed to accommodate the occurrence of unexpected events in ways that both parties feel meet their expectations and obligations.

These notions inform a number of contractual initiatives around the world. The case of the UK, where this research was based, is emblematic in this regard. The New Engineering and Construction Contract (NEC), first published in 1993 by an independent commission, aims to improve contracts along three dimensions-flexibility, clarity, and simplicity-as well as to stimulate good project management. In its current version, NEC positions itself as "a modern day family of standard contracts that truly embraces the concept of partnership." It introduces notions such as "trust," "working together," and "cooperation in planning." About two years later, British Petroleum received an "Innovation in Industry" award for its relational contracting strategy at the Andrew facilities alliance project, a North Sea oil field development; ${ }^{25}$ and a British industry-government initiative produced the Latham report Constructing the Team. The latter rang alarm bells in a construction industry characterized as "adversarial" and "incapable of delivering for its customers." The follow-up Rethinking Construction report, presented by Sir John Egan ${ }^{26}$ in 1998, spelled out a number of proposals for driving modernization of the industry. These were directly influenced by suggestions (by such Western firms as Chrysler) that the achievements of Toyota were transferable and not culture-bound. ${ }^{27}$ In particular, Rethinking Construction exhorted project clients to replace competitive tendering of the suppliers with long-term partnerships, sustained through performance measurement and incentives for continuous improvement. A subsequent report, Accelerating Change, further encouraged clients to move towards integrated teams made up of existing supply chains. Once successfully formed, the teams move from one project to the next, taking their experience and a culture of continuous improvement with them. 
A similar ethos informs the contemporaneous development of Alliance Contracting in Australia, defined as an "incentive-based relationship contract in which the parties agree to work together as one integrated team in a relationship that is based on the principles of equity, trust, respect, and openness." 28 This approach exhorts project clients to select suppliers based on cultural fit and technical competence rather than price, and to craft a culture encouraging shared behaviors and future strategizing. The latter notion combines a forward-looking projection of ends-involving projecting feelings, concerns, issues, and "strange conversations" 29 - with a visualization of how the projected future might be accomplished. ${ }^{30}$

In the U.S., the use of relational contracts is being pioneered by Sutter Health (a system of nonprofit hospitals and doctors' groups in northern California) as a means to enable parties to work collaboratively in its $\$ 5.5$ billion capital development programme. ${ }^{31}$ Likewise, BAA also deemed a relational contract fundamental for encouraging the T5 suppliers to achieve "exceptional performance ... new standards, both in the building of the facilities and in the built facilities." Hence, the T5 agreement— the "absolute bedrock of getting the relationships right" in BAA terms-aimed at creating incentives for "positive problem-solving behaviors that would not allow things to go wrong in the first place." It discarded confrontational clauses seeking to pass the blame and recover money from suppliers if things went wrong. This ethos was explained by the T5 lawyer:

"We cannot load suppliers with risk, drive prices down, and complain this is costing us more than we thought. It's fundamentally dishonest and economically illiterate. Our approach is: we can drive prices down by removing inherent waste and allowing suppliers to have a decent return just like us. We're trying to align interests. If you make it in someone's interest to do well they will, if you don't they won't."

\section{Enabling Client-Supplier Cooperation: The T5 Project}

Research on the Toyota production system has shed light on the technical processes and business infrastructure supporting the long-term cooperative relationships between assemblers and suppliers. In this system, first-tier suppliers (who work directly with and ship parts to the assembler) are not selected on the basis of bids, but rather on the basis of past relationships and a proven record of performance. Essential assembler-supplier arrangements include:

- agreements on cost-reduction targets and expectations of continuous improvement;

- trust-building practices such as transferring employees, guest engineers, and face-to-face interaction;

- sourcing work from fewer but highly competent suppliers;

- investments in relation-specific assets to enhance productivity and collaboration; and 
- routines to share technical knowledge and confidential information. ${ }^{32}$

Embedding these arrangements in a business infrastructure of long-term, flexible contracts-that adjust to split economic gains fully as market conditions change, or, as Womack et al. put it, that enshrined the mutual interdependence in the agreed-upon rules of the game ${ }^{33}$-generates a sense of mutual trust and commitment. It also encourages transparency, reciprocity, and risk sharing. Trust becomes an outcome of the reliability demonstrated over repeated interactions, as well as of the shared knowledge that the parties need one another.

Unlike assemblers, infrastructure promoters tend to have limited design and production capabilities in-house to deliver projects. In choosing instead to position themselves as the project clients, they acquire a role akin to other systems integrators-firms that constantly look for ways to use the capabilities of the suppliers efficiently so as to best meet the needs of the customers and remain competitive. ${ }^{34}$ This perspective helps to make sense of the decision that BAA made to adopt a relational contract to enable Japanese-style partnerships in the $\mathrm{T} 5$ project. The principles of streamlining production processes and creating value for customers are at the core of the lean paradigm. Likewise, two notions-improve the efficiency of the T5 suppliers; and create value for the T5 customers (e.g., airlines, statutory authorities, BAA business units)—were at the core of the business strategy for new capital developments at BAA.

\section{The Production Strategy for the T5 Project}

Inter-firm cooperation and sharing of technical knowledge and confidential information were prerequisites for institutionalizing a production strategy on the T5 project. Influenced by the Toyota practice of setting up an operations management consulting division to acquire, store, and diffuse knowledge, ${ }^{35}$ BAA hired a team of consultants specialized in lean production. The consultants were tasked to visit the suppliers' facilities and assist them in improving productivity and quality. BAA did not charge the T5 suppliers for the consultants' time, but expected suppliers to share confidential data on their production processes and costs. The consultants would then apply value stream mapping to examine the processes and find ways to help the T5 suppliers achieve the following objectives: reduce variability in production and installation rates; identify critical information flows and feedback loops; eliminate non-value-added activities; reduce lead times and batch sizes of manufacturing releases; coordinate work flow between feeder and primary workstations; and maximize the number of deliveries of materials and components just-in-time for assembly on the construction site. Further, BAA sought to emulate the way in which networks of Toyota suppliers facilitate the distribution of know-how and reduce information asymmetries. ${ }^{36}$ Hence, it institutionalized a T5 supplier "buy club" that operated on the assumption that the suppliers would share confidential cost data for products that they were regularly buying.

In an effort to emulate the asset-specific investments by suppliers in Japanese-style partnerships, BAA and selected T5 suppliers built two logistics centers adjacent to the construction site. These centers included bays of trailer parking 
to handle road transport or transfers from rail. They also included a covered manufacturing and assembly facility with overhead cranes and drive through access for consolidating materials and pre-assembling building components. By providing storage and lay down areas for raw materials, the centers allowed site construction to be buffered from variations resulting from road transportation.

Further, BAA, the consultants, and a few suppliers (the first to get involved in the project) together developed a production-planning tool, termed ProjectFlow. ${ }^{37}$ This tool encouraged the suppliers to pull materials from the logistics centers, and to produce materials on demand. ProjectFlow aimed to help "deliver today what will be installed tomorrow" akin to the lean just-in-time maxim. Further, it aimed to improve the reliability of the suppliers' production plans by ensuring that, first, the inputs for a new task were ready when needed for the task; and second, the reasons that planned tasks were not completed would become visible.

BAA and some T5 suppliers also cooperated in setting up a Kanban-like system, influenced by a similar practice in the Toyota factories. This allowed people on the $\mathrm{T} 5$ site to place an order which would trigger a request to deliver a product from one of the logistics centers (or from a marketplace/shared store for small tool replacements and consumables like water-proof suits) with the help of lorries performing "milk runs," or compound deliveries. Reorder points and maximum levels of inventories for commodities were reset periodically in accordance with replenishment lead time and forecast consumption rates.

BAA also required cooperation and flexibility from the T5 suppliers to accommodate design change requests over time, cognizant that the project requirements would need to flex in order to evolve with the needs of the T5 customers. Foreseeable uncertainties included the speed of the evolution towards ticket-less air travel, developments in the technology for handling baggage and airport security, new aircraft designs, and changes in the business models of the airlines. BAA institutionalized the demand for flexibility through a postponement policy, termed the "last responsible moment" (LRM). This allowed BAA to delay design decisions until a date after which, if a decision was not made, BAA would have to accept a negative impact on the estimated costs or baseline schedule. This procedure was integrated with a stage-gate approach. ${ }^{38}$ Formal approvals were the gateways through which the sub-projects had to pass to move from one stage to the next. BAA reserved the right to change the design before D-day, a period it termed "design evolution." To pass the D-day review, the sub-project teams needed to develop a production plan exhibiting 90 to $95 \%$ design completion and price certainty. Its approval released the funding needed to do the work.

Finally, BAA sought to incorporate many of the sociological features of Japanese-style partnerships in the T5 organization. Physical proximity is a key enabler of relational rents as it facilitates the establishment of knowledge-sharing routines and inter-firm cooperation. ${ }^{39}$ Hence, BAA and the T5 suppliers (a designation which BAA used equally to refer to architects, engineering consultants, contractors, and manufacturers) were co-located at the T5 site. Other 
efforts to create a shared purpose and build a sense of collective identity with the suppliers' staff ("there weren't lots of people on site, there were T5 people on site," emphasized the T5 commercial director) included giving everyone a T5-email address (@t5.co.uk), funding a monthly site newspaper (The Site), seconding suppliers' staff to work for the BAA T5 team (a de facto transfer of employees), and establishing inter-firm committees for quality, health, and safety. BAA also coined the term "T5 preferred supplier" to help the suppliers draw reputation benefits, and signed framework agreements with the suppliers to give them prospects of a long-term collaboration.

\section{The Design of the T5 Agreement}

The ethos informing the design of the T5 agreement was about creating an environment where "attitudes and roles bedeviled with concern about exposure to risk, unbalanced focus on capital cost, lowest costs, and layers of practices that inhibit change are unacceptable," as stated in the contract. The contract also recognized that the targets for the $\mathrm{T} 5$ project were aggressive and urged suppliers to change work practices:

“Thinking of others as well as oneself, so that we [BAA and suppliers] all win together, is a must. Being able to see the wider benefits will entail a change of mindset, possibly changing out people; there will be little room for those who are not committed, who want to spend all their time saying 'why it can't be done.'" -T5 Agreement

The BAA ideal was that the suppliers would achieve "exceptional performance," i.e., they would be better than anything anyone else had achieved before. The contract further added:

"Best practice is the minimum level of performance that we require people to commit to. While this is a step up from the normal levels of performance required, 'business as usual,' this should not be a problem. We have procured companies and people on the basis that you are experts in your field; you are leaders in your industry; you are making available people and skills committed to this expected level of performance."

The principle for remunerating the suppliers, as spelled out in the commercial policy, was reimbursable cost of time and materials plus an agreed profit margin. The $\mathrm{T} 5$ contract manager explained the rationale:

"The fact that we're paying people by the hour allows us to be pretty flexible in using resources, and changing and moving things quickly around ... We'll give suppliers a level of profit for the tasks we can see ahead of us, but suppliers won't be taking any of the risks of inefficiency or overspend. This is a very positive environment. Suppliers may not make their best returns here, but they aren't making any loses."

The T5 suppliers were expected to demonstrate to BAA that the costs had been properly incurred. BAA reserved unfettered rights to carry out reviews to audit supplier accounts, staff and labor payrolls, purchase ledger systems, volume discounts, retrospective rebates, early payment discounts, and cash flow 
statements. (This is known as the "open book regime"). Occasionally, BAA and the suppliers could agree to fixed rates or lump sums for specific elements of work, based upon clarity of scope and utilization of standard products. Still, three details designed into the contract could have major impacts on the profit mark up to be made by the suppliers: ring-fenced profit, incentive plan, and compensation for changes.

\section{Ring-Fenced Profit}

The contract spelled out that the suppliers' profit was "ring-fenced," as an agreed lump sum amount against an agreed estimate of resources for a defined scope of work. Suppliers could increase their profit margin percentage by delivering their work at a cost less than the estimate. Conversely, the profit margin could shrink if the estimate of resources was too optimistic relative to the actual amount of work needed to deliver the defined scope of work.

\section{Incentive Plan}

Influenced by the use of target costing in Toyota, the commercial terms aimed to provide incentives for suppliers to "realize the client ambitions" and exceed the "client's expectations." Thus, BAA contractually agreed to share benefits of exceptional performance 50:50 with the first-tier suppliers. The benefits were calculated as the difference between the baseline target cost and the actual cost of work. Target costs were agreed to with the suppliers involved in the design and implementation. The targets were meant to reflect benchmarks, yardsticks and norms free of allowances and contingencies for inherent construction risks.

\section{Compensating for Change}

The way BAA categorized a change request impacted the profit margin of the supplier. Changes that BAA described as "design evolution" meant that, in the view of the T5 agreement, they did not alter the design scope:

“Evolution isn't change. . . . managing the ambiguities between the objectives, potential solutions, and delivery practices is a basic requirement of your and our delivery practices. This requires delivery plans and actions to evolve and adapt through the project. This evolving and adapting activity does not constitute change, but may involve transferring responsibilities, budgets, time, etcetera, between teams and team members."-T5 Agreement

Thus, BAA did not amend the ring-fenced profit in response to design evolution-while suppliers were reimbursed for the actual costs incurred with additional work stemming from design evolution, their profit margin was reduced. Conversely, BAA considered as "exceptional" all the events and issues changing the project scope. In these circumstances, BAA would sanction the change and amend the ring-fenced profit so as to keep unaffected the agreed supplier's profit margin. Conversations between BAA and the suppliers preceded the categorization of an event as design evolution or change in scope. 
While the ethos of the T5 agreement was undoubtedly relational, and BAA administrators insisted that "there was no better deal on the market," the fieldwork repeatedly uncovered tensions associated with the implementation of the contracting strategy. The findings also revealed that occasional poor management of these tensions could hinder cooperative work, in essence defeating the purpose of the contract. BAA respondents tended to frame the difficulties mostly as a cultural issue: "our biggest challenge is educating and working with suppliers and getting them to see the vision," argued the T5 project director. This message was echoed by the T5 lawyer, "the industry has to believe in what it's being told, suppliers are looking for catches that aren't there, and some don't understand." Surely, studies demonstrate the importance of aligning the systems and cultures of the buyers and suppliers for facilitating coordinated action and generating relational rents. ${ }^{40}$ Studies of efforts to implement the Toyota Production System by U.S. firms, in particular, highlight the "very long time and tremendous commitment" involved whenever total cultural and organizational changes are required. ${ }^{41}$ Still, the fieldwork revealed that the actual ways used to implement the T5 agreement also affected its capability to encourage inter-firm cooperative work: "It's very easy to write the words, to sell the concept, but how to actually make it work is really tough," alerted a project director. ${ }^{42}$

\section{Making Relational Contracts Work in Projects}

The air traffic control steel tower would rise ultimately to 87 meters high. When its first two sections were manufactured, they were out of specification by $9 \mathrm{~mm}$, placing the project at risk. The T5 managing director noted, "Normally, the manufacturers would have blamed the structural engineers, who would have blamed the steel fabricator. At first, they did just that. . . . but the T5 agreement allowed me to say "Guys, this is my problem," and send them off to find a collective solution." 43

The incident above has been told and retold countless times by the T5 project administrators when seeking to illustrate how the contract enabled cooperative work and helped to avoid the typical "contractual bloodbaths." Its positive tone is corroborated by evidence that I gathered from the suppliers about how they systematically assessed the effectiveness of the T5 agreement (summary in Table 1). As one supplier project director put it:

"If you try to manage a project of this size as a conventional project, you'd need a line of lawyers, we'd go to court and sue the hell out of each other. Whereas here, there's a lot of negotiation going on with the client. But, at the end of the day, we'll be happy because we don't have this conflict. It's not adversarial, it's a good way to work."

The in-depth fieldwork confirmed, however, the adage that the devil is in the details. When the five factors discussed next were overlooked, the effectiveness of the relational contract was limited-as it happened occasionally at T5.

- Project suppliers are keen to reap reputation benefits.

- Project suppliers have flexibility in their production processes. 
TABLE I. Excerpt of Data on Suppliers' Assessment of the T5 Agreement (cost and manpower data valid for 2005)

\begin{tabular}{|c|c|c|c|c|}
\hline (\#) & $\begin{array}{l}\text { Supplier } \\
\text { Profile }\end{array}$ & $\begin{array}{l}\text { Supplier Size } \\
\text { Relative } \\
\text { to the T5 Work } \\
\text { Package }\end{array}$ & $\begin{array}{l}\text { High- } \\
\text { Level } \\
\text { Assess- } \\
\text { ment }\end{array}$ & Exemplar \\
\hline । & $\begin{array}{l}\text { Small } \\
\text { domestic } \\
\text { ductwork } \\
\text { contractor }\end{array}$ & $\begin{array}{l}\text { T5 was the largest } \\
\text { project the supplier } \\
\text { had ever undertaken }\end{array}$ & $\begin{array}{l}\text { Moderately } \\
\text { Positive }\end{array}$ & $\begin{array}{l}\text { "Even if uncertainty has been a problem for } \\
\text { us - our system is not geared up for that as all } \\
\text { our projects have to be fed in by the factory- } \\
\text { at the end of the day, we'll be happy with the } \\
\text { project because it's not adversarial."--Project } \\
\text { Director }\end{array}$ \\
\hline 2 & $\begin{array}{l}\text { Domestic } \\
\text { provider of } \\
\text { steelwork } \\
\text { solutions } \\
\text { (design, } \\
\text { fabricate, } \\
\text { and install) } \\
(\sim 1200 \text { staff) }\end{array}$ & $\begin{array}{l}\text { T5 was a "huge" } \\
\text { project, representing } \\
50 \% \text { of its annual } \\
\text { capacity at peak }\end{array}$ & $\begin{array}{l}\text { Very } \\
\text { Positive }\end{array}$ & $\begin{array}{l}\text { "It [T5 Agreement] allowed us to be less } \\
\text { defensive, to bring to the table more issues; } \\
\text { it reduced conflict... our voice was just as } \\
\text { important and valued as anyone else's."- } \\
\text { Project Director }\end{array}$ \\
\hline 3 & $\begin{array}{l}\text { Global } \\
\text { general } \\
\text { contractor } \\
(\sim 20,000 \\
\text { staff })\end{array}$ & $\begin{array}{l}\text { T5 represented a } \\
\text { turnover of around } \\
£ \text { Ibn over } 4 \text { years } \\
\text { for firm with annual } \\
\text { turnover } \sim € 1.8 \mathrm{bn}\end{array}$ & $\begin{array}{l}\text { Very } \\
\text { Positive }\end{array}$ & $\begin{array}{l}\text { "It [T5 agreement] is very much a true } \\
\text { partnering arrangement. The essence of what } \\
\text { people are trying to do is the right thing to do. } \\
\text { Doing it differently, BAA would be getting lots } \\
\text { of claims, and would be more difficult."-Project } \\
\text { Director }\end{array}$ \\
\hline 4 & $\begin{array}{l}\text { Global } \\
\text { structural and } \\
\text { engineering } \\
\text { consultant } \\
\text { ( } \sim 9,000 \text { staff) }\end{array}$ & $\begin{array}{l}\text { T5 was but one of } \\
\text { many large-scale } \\
\text { projects around the } \\
\text { world }\end{array}$ & $\begin{array}{l}\text { Very } \\
\text { Positive }\end{array}$ & $\begin{array}{l}\text { "It [T5 agreement] gets people to buy early } \\
\text { on to the concept of working together, creates } \\
\text { a much better environment to do challenging } \\
\text { work, allows to solve problems without issues of } \\
\text { running out of fee."--Project Director }\end{array}$ \\
\hline 5 & $\begin{array}{l}\text { Global } \\
\text { provider } \\
\text { of curtain } \\
\text { walling and } \\
\text { roof solutions } \\
\text { (design, } \\
\text { fabricate, and } \\
\text { install) ( } 750 \\
\text { staff) }\end{array}$ & $\begin{array}{l}\text { Largest project ever } \\
\text { done, but involving a } \\
\text { small fraction of the } \\
\text { production capacity } \\
\text { of the } \sim £ 20 \mathrm{~m} \text { annual } \\
\text { turnover company }\end{array}$ & Negative & $\begin{array}{l}\text { "To be honest, it [T5 agreement] didn't work } \\
\text { very well for us. We're used to get a package } \\
\text { of information, and we hit the ground running. } \\
\text { Here, it wasn't a blank paper, but a lot needed } \\
\text { working through. It was very difficult for us, a lot } \\
\text { of conflict."-Project Director }\end{array}$ \\
\hline 6 & $\begin{array}{l}\text { Global } \\
\text { provider of } \\
\text { engineering } \\
\text { and building } \\
\text { services } \\
\text { ( } 27,000 \\
\text { staff) }\end{array}$ & $\begin{array}{l}\text { T5 represented } \\
\text { about } \sim £ 50 \mathrm{~m} \text { of } \\
\text { the } \sim £ 5 \mathrm{bn} \text { annual } \\
\text { turnover; it didn't } \\
\text { make top ten } \\
\text { lists by volume or } \\
\text { contribution on } \\
\text { turnover; }\end{array}$ & Negative & $\begin{array}{l}\text { "The T5 agreement is about obtaining from } \\
\text { suppliers capacity and that's too loose... It has } \\
\text { left the choice on what would be contractually } \\
\text { accepted to the interpretation of the parties } \\
\text { and largely in the judgment of BAA, which } \\
\text { creates some mistrust and-if the job is not } \\
\text { going right- - some fear."-_Project Director }\end{array}$ \\
\hline
\end{tabular}


TABLE I. Excerpt of Data on Suppliers' Assessment of the T5 Agreement (cost and manpower data valid for 2005) (continued)

\begin{tabular}{|c|c|c|c|c|}
\hline (\#) & $\begin{array}{l}\text { Supplier } \\
\text { Profile }\end{array}$ & $\begin{array}{l}\text { Supplier Size } \\
\text { Relative } \\
\text { to the T5 Work } \\
\text { Package }\end{array}$ & $\begin{array}{l}\text { High- } \\
\text { Level } \\
\text { Assess- } \\
\text { ment }\end{array}$ & Exemplar \\
\hline 7 & $\begin{array}{l}\text { Global } \\
\text { provider of } \\
\text { structural } \\
\text { and civil } \\
\text { engineering } \\
\text { services } \\
(\sim 13,000 \\
\text { staff) }\end{array}$ & $\begin{array}{l}\text { T5 was but one of } \\
\text { many large-scale } \\
\text { projects around the } \\
\text { world }\end{array}$ & $\begin{array}{l}\text { Very } \\
\text { Positive }\end{array}$ & $\begin{array}{l}\text { "I cannot see how you could do this job in a } \\
\text { different way. Although it's a framework and } \\
\text { cost reimbursable, the process is managed and } \\
\text { controlled."-Project Director }\end{array}$ \\
\hline 8 & $\begin{array}{l}\text { Domestic } \\
\text { roofing and } \\
\text { cladding } \\
\text { contractor }\end{array}$ & $\begin{array}{l}\text { Average turnover of } \\
£ 30 \mathrm{~m} ; T 5 \text { was largest } \\
\text { project firm ever did, } \\
\text { representing } \sim £ 40 \mathrm{~m} \\
\text { over } 4 \text { years }\end{array}$ & $\begin{array}{l}\text { Very } \\
\text { Positive }\end{array}$ & $\begin{array}{l}\text { "It [T5 agreement] is less confrontational; } \\
\text { people are being paid to coordinate interfaces, it } \\
\text { made possible co-location, problems are easier } \\
\text { to solve in a non confrontational way."--Project } \\
\text { Director }\end{array}$ \\
\hline 9 & $\begin{array}{l}\text { Global } \\
\text { provider } \\
\text { of baggage } \\
\text { handling } \\
\text { systems } \\
\text { ( 1200 staff) }\end{array}$ & $\begin{array}{l}\text { Average turnover } \\
\text { of } \sim £ 275 \mathrm{~m} ; 75 \text { was } \\
\text { extremely important, } \\
\text { representing } \\
\sim £ 300 \mathrm{~m} \text { over } 5 \\
\text { years }\end{array}$ & $\begin{array}{l}\text { Very } \\
\text { Positive }\end{array}$ & $\begin{array}{l}\text { "It [T5 Agreement] does work. It doesn't mean } \\
\text { there's no conflict or disagreement, but it allows } \\
\text { resolving problems rather than trying to push } \\
\text { blame or point a finger."--Project Director }\end{array}$ \\
\hline 10 & $\begin{array}{l}\text { Domestic } \\
\text { production } \\
\text { architectural } \\
\text { practice ( } 80 \\
\text { staff) }\end{array}$ & $\begin{array}{l}\text { Very important } \\
\text { project aligned with } \\
\text { the core business } \\
\text { activity (airport } \\
\text { design) }\end{array}$ & $\begin{array}{l}\text { Very } \\
\text { Positive }\end{array}$ & $\begin{array}{l}\text { "I'm a firm believer in it [T5 agreement]. } \\
\text { However, as an individual, I generally believe } \\
\text { we'll get the best results if we work together- } \\
\text { so it hasn't changed the way we work."-Project } \\
\text { Director }\end{array}$ \\
\hline 11 & $\begin{array}{l}\text { Domestic } \\
\text { services } \\
\text { design and } \\
\text { engineering } \\
\text { consultant } \\
(\sim 200 \text { staff })\end{array}$ & $\begin{array}{l}\text { Very important } \\
\text { project }\end{array}$ & $\begin{array}{l}\text { Moderately } \\
\text { Positive }\end{array}$ & $\begin{array}{l}\text { "It [T5 Agreement] helps because you've a } \\
\text { partnering agreement, but if someone wants } \\
\text { to be disruptive, the process can be difficult. } \\
\text { Sometimes peer pressure works quite well, } \\
\text { other times not so much."--Project Director }\end{array}$ \\
\hline 12 & $\begin{array}{l}\text { Global } \\
\text { fabricator and } \\
\text { installer of lifts } \\
\text { and escalators } \\
(\sim 30,000 \\
\text { staff) }\end{array}$ & $\begin{array}{l}\text { T5 was one of many } \\
\text { large-scale projects, } \\
\text { representing } \sim 3 \% \text { of } \\
\text { annual turnover }\end{array}$ & $\begin{array}{l}\text { Moderately } \\
\text { Positive }\end{array}$ & $\begin{array}{l}\text { "I think the T5 agreement works reasonably well, } \\
\text { but not without its frustration. There's too much } \\
\text { dabbling, which isn't good. When a design is } \\
\text { done, they need to say 'that's it, no more looking } \\
\text { and playing."'-Project supplier }\end{array}$ \\
\hline 13 & $\begin{array}{l}\text { Design and } \\
\text { management } \\
\text { consultant } \\
(\sim 1,500 \text { staff })\end{array}$ & $\begin{array}{l}\text { T5 was very } \\
\text { important for a } \\
\text { firm growing rapidly } \\
\text { (from } £ 90 \mathrm{~m} \text { annual } \\
\text { turnover } / 200 \text { I to } \\
£ 500 \mathrm{~m} / 2007 \text { ) }\end{array}$ & $\begin{array}{l}\text { Moderately } \\
\text { Positive }\end{array}$ & $\begin{array}{l}\text { "It's all very aspirational, excellent stuff, but the } \\
\text { trouble is you only need one person to say 'l'm } \\
\text { not going to play, and things stop. We need a } \\
\text { sort of hierarchy in decision making"-Design } \\
\text { leader }\end{array}$ \\
\hline
\end{tabular}


- Project client and suppliers choose the right people for the jobs.

- Project client learns to contract in response to supplier feedback.

- Project client aligns practices to control and improve performance with supplier skills.

\section{Suppliers Are Keen to Reap Reputation Benefits}

Reputation is an integral part of a relational contract, but the empirical findings reveal that it is not relevant in the same way for all the project suppliers. In effect, the capability of a relational contract to encourage cooperative work is limited if the suppliers are indifferent as to whether they can reap reputation benefits from project participation or not. Some T5 suppliers, for example, were strategically interested in growing their domestic business (e.g., Firms \#2, $\# 3$, \#13), whereas others were interested in establishing a presence in the world of airport projects (e.g., \#9, \#10). The iconic presence of the Heathrow airport expansion, in the UK and in the airport sector in general, meant that these suppliers committed to ensure that their work in T5 would be well regarded. This, in turn, meant that the corporate administrators of the suppliers were keen to become actively involved with the work. This engagement of senior administrators was instrumental for encouraging and empowering project staff to replace the more traditional confrontational practices on site with cooperative behavior.

Hence, the T5 agreement was particularly successful in encouraging the firms for which T5 could be a spring board for success to work cooperatively, firms for which the volume of work in T5 could occasionally represent up to $30-50 \%$ of their annual turnover. The principles of the production strategy, for instance, were totally taken on board by Firm \#3, which reported cutting down the storage for concrete materials from 3 weeks to 3 days, and increasing the reliability of the planning activities from $50-55 \%$ to $80-85 \%$ over time. It also reported cutting down the lead time to produce a pile (out of 39 types) from 10 weeks to 7 days, making foundations work highly adaptable to late change. In 2007, the CEO of the firm (by then a $£ 4$ bn turnover business) would publicly state:

"T5 is probably the watershed project of my career, the only way to do things. The non-fiscal value to us gained from working under the T5 Agreement is extraordinary and I would not now willingly work in any other way."

Likewise, the implementation of the T5 agreement was effective with the supplier providing the $£ 300 \mathrm{~m}$ baggage handling system (Firm \#9). T5 was a business-critical project for this supplier due to the visibility it would bring in the world of airport projects-"I think all eyes of the world are fixed on T5," remarked its site manager after reckoning that no more than five suppliers worldwide had capabilities to undertake the project. This made senior administrators readily available to resolve any tensions and to ensure that the partnership worked. Conversely, the T5 agreement was less effective in encouraging other large firms to work cooperatively-firms for which, first, the T5 work 
represented a fraction of their annual turnover; and second, getting a foothold in the airports market was not a strategic priority:

“Reputation doesn't figure heavily here. We [buildings and service division] signed up to the contract because we didn't want to be out of this job, and in that way, perhaps we can say that the big firm couldn't. But we won't accept a lower return in this job. Being a large, diverse firm, you can afford to lose big clients because you aren't totally dependent-we cry over, we're annoyed, but that doesn't destroy us."-Project Director, Firm \#6

Hence, BAA failed to persuade some large contractors and manufacturers (e.g., \#5, \#6) to adopt the principles of pulling and planning reliability, as well as the ProjectFlow tool, despite the benefits reportedly stemming from its application to other subsystems. Notwithstanding, the T5 agreement succeeded in encouraging a few other large suppliers to adopt the principles of the production strategy.

\section{Suppliers Have Flexibility in Their Production Processes}

A core motivation underpinning the adoption of a relational contract is encouraging project suppliers to be flexible to accommodate client-driven requests to change the design or the construction sequences. The findings suggest, however, that the effectiveness of a relational contract in this regard is limited by the degree of flexibility in the production processes of the suppliers. By nature, the T5 engineering consultancies and architectural practices were flexible enough to accommodate change and postpone design decisions. Accordingly, fewer commercial tensions emerged when BAA requested them to do so:

"As a designer coming on to the party, the T5 agreement means we get paid on people's costs. We negotiated our rates-we obviously would like those to be more [laughs] - and we get paid for what we do. For us, it's about delivering the project in collaborative work. We don't use financial incentives to motivate people. Our guys are doing it for the kudos of being at T5."- Project Director, Firm \#10

Conversely, the T5 suppliers of manufactured components (e.g., Firms \#5, \#12) disliked the notions of design evolution and postponement institutionalized through the last-responsible-moment policy. Unlike the autonomy exhibited by the site teams of design consultants relative to the head offices, the site teams for the manufacturers needed to coordinate their plans with the production schedules for their factories. Because the factories invariably served a number of projects at any time, the site managers were under pressure to commit to specific production slots months in advance in order to optimize the utilization of the fixed assets:

"We're quite rigid, we've lead times for our profiles, we've got to cut new dies, to extrude aluminium that gets delivered to our factory, etcetera. The capacity chart of our factory is filled in early on. Once we [project] get a production slot, we've to stick with that. You need to feed the machine, you need decisions on colour, glass selection, and that's the way it has to be."-Project Director, Firm \#5 
Thus, the T5 suppliers operating rigid production processes found it hard to cooperate with the change requests. In essence, the supplier staff believed it would be hard to recoup the full cost of disrupting production due to a BAA change request since it would be difficult to distinguish the costs attributable to the client intervention from those normally due to the activities for which supplier was responsible. ${ }^{44}$

The fieldwork also suggested that the resistance to change that a few firsttier suppliers exhibited was in part because BAA had ring-fenced their profit against an agreed estimate of resources for a defined scope of work. Hence, late changes reduced the chances that suppliers could make the originally agreed profit margin unless BAA adjusted the maximum lump sum to compensate for the additional work. However, BAA was unlikely to do so unless it felt that the change altered the scope given that the contract assumed that suppliers were flexible in accommodating changes associated with design evolution:

"Our view is-and perhaps I'm being rather contractual but it's in the nature of the beast that we're-you can only do cost estimates on what you see. The interpretation of loose agreements in terms of whether it's change of scope or design development causes lots of untidy discussions. It leads to the wrong type of behavior, including protectionism and documenting all the issues. You start doing what you shouldn't be doing." —Project Director, Firm \#6

Over time, BAA realized that the contract alone would not eliminate commercial tensions and encourage cooperative work. BAA staff needed to understand how to adjust and interpret it when managing the issues. As a BAA production manager stated in regards to requesting late changes "when you issue changes, you've to be careful. You've to listen to suppliers if you're giving more work but not giving more profit." Likewise, BAA also needed to ensure that staff working for the suppliers stayed attuned to the relational principles when searching and negotiating solutions for adverse situations.

\section{Client and Suppliers Choose the Right People for the Jobs}

The empirical findings revealed that the limited financial risk borne by the T5 suppliers did not suffice to offset the goal of some suppliers' staff for making higher returns. Evidence suggests that this misalignment of expectations could drive two responses deleterious to working cooperatively. On some occasions, the supplier administrators agreed to the $\mathrm{T} 5$ deal but found it hard to assign to $\mathrm{T} 5$ the most competent managers who were unimpressed by what BAA termed "decent profit." Rather, the latter would prefer to work for projects gained through competitive bidding. Those environments offered them more opportunities to leverage their skills in getting the work done for less than the prices spelled out in the bid:

“BAA looks from this view 'you, Mr. Supplier, have guaranteed all reimbursable costs plus a ring-fenced profit, and you'll get an additional reward if cost comes below target.' The opposite side of the coin, and a lot of people here fail to acknowledge it, is that some suppliers are so efficient or have so much prestige that they can do much better than this."-Design Coordinator 
Alternatively, suppliers could assign some competent individuals to the project. However, these individuals could fail to grasp the ethos of the T5 agreement if they had been accustomed to working in adversarial environments. One supplier project director, although cognizant of the limited financial risk incurred, asserted: "we go for this type of contract for a higher margin, so we need to support the contract with visible means on how exceptional money reward can be accomplished. Otherwise why not stick with lump sum forms of contract that have been used for 200 hundred years? This needs to be a win-win."

The takeaway point here is that not all individuals are fit to operate in the cooperative environment that a relational contract aims to encourage. It would also be naive to expect induction workshops on relational contracts (and peer pressure from other suppliers) to automatically change behaviors. Hence, the risk is high that the wrong individual's attitude ripples through the project team, and jeopardizes the effectiveness of a relational contract. Clients and suppliers both need to assess whether staff choices fit into the culture of cooperative work under uncertainty and ambiguity. They must also not shy away from replacing project staff who turn out to be incapable of acquiring the mindset required.

One practice that BAA later implemented to reduce the errors of choosing the wrong people was asking each team of suppliers to deliver a 25-minute presentation as part of the selection process. The supplier teams were to include the executive director, the prospective project/design leaders, and the prospective cost manager. For the presentation, the teams had to pretend to be moving forward in time and had to imagine a situation where they had gained a "best T5 supplier" award after doing the work. The presentations should describe "retrospectively" the journey toward the award, resembling narratives of future perfect thinking reported elsewhere ${ }^{45}$ The supplier that BAA ultimately selected for delivering the ceilings package, for example, started its presentation as follows:

“It wasn't us and you [BAA]. We thought out of the box and provided leadership; a direct contact with you produced better understanding of what was required. We learned a lot from you, we learned together, we respected and felt respected, we worked with passion doing what we like to do, and this was essential to reduce costs and deliver value."-Project Director, supplier presentation, 2006

\section{Client Learns to Contract in Response to Supplier Feedback}

Learning to contract is an incremental and local process (seldom very far sighted) that occurs over a long period time. ${ }^{46}$ This means that the project client is unlikely to get the written commercial details of a relational contract right at the first attempt. Rather, ex-post capabilities to interpret and adapt the contract are crucial to making it work as the project progresses. The value of learning was particularly conspicuous in the trial-and-error process that BAA and the suppliers went through in attempting to institutionally implement the principle of rewarding the T5 suppliers for performing exceptionally well. The underlying idea was to allow the suppliers to reap monetary rewards when they executed the work at a cost below the target cost. However, the extent to which this 
incentive actually worked depended on whether it met two major concerns of the suppliers. The first pertained to the extent to which BAA would distribute the incentives close to the date when the suppliers had completed their work; and the second pertained to the extent to which the cost targets would be realistic.

Crafting an incentive scheme that would address the first concern turned out to be difficult for the cross-functional teams involving representatives of BAA and T5 suppliers. ${ }^{47}$ The original scheme set the incentives at an overarching project level and operated on the assumption that rewards would be distributed when the project reached completion. This was criticized by many suppliers for being too intangible and failing to motivate. By the time a project gets completed, the suppliers argued, a lot of their staff will have left the project, perhaps even moved to other employers, which undermined the spirit of the incentive. Subsequently, BAA altered the incentive scheme, allowing for distributing rewards right after completing a subproject. However, this new design lessened the capability of the scheme to encourage suppliers to work cooperatively across subprojects and, in particular, to accommodate in the late project stages work that had gone unnoticed in the early stages. These "scope gaps," inherent in the execution of complex projects, were the outcome of interfaces between subprojects that had been overlooked in the design stage. A common story I heard is illustrated by the following example. Additional work was needed to reinforce the ground around a terminal building for taking the load of the cranes lifting the roof panels-work with a cost above $£ 1 \mathrm{~m}$ that had been overlooked when building the foundation. However, because the foundation and roofing teams operated under distinct incentive schemes, they were-understandably-reluctant to undertake the work unless BAA adjusted their targets. The contract manager would later complain that "they [the new incentivization schemes] are encouraging suppliers to fall into the old silo mentality to protect their shares." And more emphatically, a supplier noted "T5 is a bit like a number of ant nests, not quite at war with each other but all wrestling over the same territory." Subsequently, BAA decided to readjust the contract and designed an incentive scheme that operated in between the two previous schemes. Likewise, BAA also found it difficult to address the concerns of some suppliers regarding the lack of realism underlying the target costs:

“I don't think incentive schemes worked well. For every team, they first did a Monte Carlo analysis and the target was the P40 figure, but many targets came out impossible to accomplish. Further, initially the incentive was just about money. Then it was about money and time, which seems a good thing, but it got too complicated. So people tended to see targets as things that they couldn't control. I'm not aware of any incentive ever being met, so you just start relaxing and do the best you can."-Project Director, Firm \#4

Contrary to the project director's understanding above, the fieldwork actually revealed that some suppliers managed to deliver work below the target costs. Some even managed to reportedly make double-digit profit margins. The extent to which these situations were considered excessive by some people 
at BAA is an issue I discuss in the last sections. The point here is that agreeing upon reasonable target costs is quite hard when the parties do not have available banks of cost data that they can benchmark against. This situation is fairly common in large-scale engineering projects. ${ }^{48}$ It was also exactly the case with T5. Not only were its buildings of a distinctive design commissioned from a signature architectural practice, but Terminal 4, the previous extension of Heathrow, had been constructed almost 20 years before. In these circumstances, the client really needs to listen to suppliers and keep fine tuning the commercial terms as the project unfolds, or in the words of the T5 lawyer, "You shouldn't try to fix initially things that you don't know. You want to create a platform of stability from which you can be flexible to respond to new issues." In doing so, infrastructure promoters can fulfill the potential role of the contract as a repository for knowledge about how to govern inter-firm relationships.

\section{Client Aligns Practices to Control and Improve Performance with Supplier Skills}

While BAA decided to use the T5 agreement regardless of the size of the supplier organization, the implementation of some details turned out to be challenging with the smallest firms (e.g., Firms \#1, \#8, \#10, \#11). Project participation was unarguably important for these firms- "these projects don't come along every day!" explained one project director. Yet, small suppliers seldom had adequate organizational structures and procedures in place for addressing the frequent demands for detailed performance reports and cost data. Of course these demands have a raison-d'être in relational environments. Social safeguards (e.g., trust, reputation, continuity) work well against uncertainty over time, but they can be insufficient to dissuade opportunistic behavior when there is high ambiguity about available courses of action, variables, and cause-effect relationships. ${ }^{49}$ Ambiguity increases the possibility that individuals act opportunistically with limited risks of being uncovered. ${ }^{50}$ In T5, the construction director termed "vigilant trust" to the set of practices institutionalized for "never letting suppliers feel entirely comfortable in a reimbursable environment." He deemed it necessary to scrutinize how suppliers were planning the work and incurring costs, as well as to explore routinely ways to meet targets. Yet, the smaller firms were often unable to respond as BAA would expect. One supplier director argued (Firm \#8):

“Look, I'm not going to do more key performance indicators and weekly performance measurements. I don’t need these. I’ve been a £30m turnover company for many years and want to continue to be like that . . . If I over run my budget it's a problem, but I'll not change. Incentivization schemes don't get me out of bed in the morning."

Likewise, BAA found it particularly difficult at the onset to persuade some design consultants to cooperate with the demands for information because they seemed less attuned to a culture of monitoring performance and continuous improvement than contractors ("our organizations are very thin, we aren't geared up to have these formal arrangements," one argued). Logically, the lack 
of cooperation from suppliers on this matter frustrated BAA, which was incurring expenses in employing staff to monitor costs and ensure it was getting the best value for its money.

This problem suggests that project clients perhaps want to set up a scale of procedures on auditing cost data and measuring performance, and adjust the reporting obligations to the skills of the suppliers. This practice has been recently adopted by the Manchester City Council in a $£ 600 \mathrm{~m}$ program to build over 30 new schools. Like BAA, the Council opted for implementing a relational strategy and selected a few suppliers to be part of a 10-year framework agreement. In the face of a fixed and tight budget, however, the Council opted for not allocating a big "slice of the pie" to monitor and control supplier performance. Rather, it subscribed to a more economical system of random checks, which it reckoned are more compatible with its own skills and competences, as well as with those of the suppliers.

That said, infrastructure promoters still want unequivocally to signal to suppliers their expectations for continuous improvement and exceptional performance in a relational environment. This is important in avoiding the emergence of a spending culture. One way of doing so, provided the market allows, is by creating a sense of competition among the suppliers. Dyer's research in manufacturing shows that vigorous competition can be achieved with two or three equally competent suppliers for each component/subsystem as long as price benchmarking is done frequently-a practice termed "parallel sourcing." In infrastructure projects, the promoter can break the large work packages (e.g., excavation, foundations, steelwork/concrete frame, building services) across two or three suppliers. This approach can also reduce the costs of switching away from a supplier that fails to perform. BAA occasionally adopted this approach. However, in hindsight, one project director noted:

"When we set the T5 agreement, we could have broken the work packages and said to two, three suppliers 'you're all going to operate under the same agreement, and the company which performs better will get more work.' That would have been much better than saying to one supplier 'take all the work and by the way you ought to perform.'"

All in all, the design of the T5 agreement succeeded in working as an enabler of project client-supplier cooperative work. Also, whenever those responsible for the management of the agreement took account of the critical factors spelled out here, the relational contracting strategy effectively encouraged cooperative work. This, in turn, allowed BAA successfully to bring about its production strategy with some-but certainly not all-T5 project suppliers.

The fact that BAA opted to use the T5 agreement with all the first-tier suppliers created a unique opportunity to probe into the do's and don'ts of making a relational contract work. Yet, this across-the-board approach was contested by a number of parties. 


\section{Managerial Implications:}

\section{Is Relational Contracting a One-Size-Fits-All Strategy?}

One extraordinary facet of the relational contracting strategy in the T5 project is the way its across-the-board application goes against most recommendations from scholarly literature (not grounded in projects, admittedly) on transaction cost economics and strategic supplier segmentation. The former frames the problem as a choice between contracting through markets, relational governance structures, or hierarchies. This choice should be dictated by the relative efficiency in the transactions costs (i.e., cheaper forms will drive out costlier forms), which are a function of the degrees of asset specificity, frequency, and uncertainty affecting the transactions. ${ }^{52}$ The latter argues that firms need to develop the capability to segment strategically suppliers as a function of the extent to which the product/service that each supplier provides contributes to the core competences and competitive advantage of the buying firm. ${ }^{53}$

By the end of the $\mathrm{T} 5$ project, there were a number of dissenting voices within BAA regarding the choice to implement the T5 agreement across-theboard. One view insisted that the T5 project could not have been done efficiently in a different way given the flexibility to make changes that BAA had required from the onset. The T5 lawyer would emphasize in 2005, for example: "the proof of the pudding is where the project stands right now, half way through construction on time and on budget, with no major injuries, no claims." With credit to BAA, T5 opened on time and reportedly on budget on March 27, 2008, the opening date announced six years in advance. ${ }^{54}$ The other view argued that the inclusive application of the T5 agreement had failed to create enough commercial tensions with the suppliers, thereby occasioning "lazy" budgets and complacency from some suppliers:

\footnotetext{
"When we look to the new plants they built, when we feel that the size of the crews was perhaps too large, that all the equipment was brand new, that productivity was not that impressive, we think that the commercial module was faulted. Suppliers started with best intentions, but we ended up paying for everything... Where I also think it [T5 agreement] hasn't worked is when we tried to bring suppliers who were just going to be here for a short period, say 6-months. Asking people to work in a completely different way in a short period of time is difficult. At the directors' level, we can get them to buy into it, but the guy digging the hole won't be bothered."-Production Director
}

Conversely, the suppliers I interviewed almost unanimously professed that the use of the T5 agreement, paying suppliers by the hour, had been a better way to work. While it had not been perfect, recognized most suppliers, the approach had produced better results and provided BAA flexibility in using resources and getting the right people. So under which conditions do relational contracts shift from being a cost-effective enabler of inter-firm cooperative work into being a wasteful overkill, i.e., an excessive effort to achieve a common purpose? Should project clients strategically segment suppliers instead? If so, how do alternative contract designs match to different inter-firm project relationships? The research base here does not lend itself to resolving these questions, 
even though it reveals variations across suppliers' behavior and performance, as well as adjustments made to pay structures in response to supplier feedback. The desirable situation, of course, would be to have framings and tools tested and readily available that managers could use to carry out step-by-step negotiations and to better respond to conflict and disputes in relational project environments. This gap offers an opportunity for researchers interested in how organizations can effectively change contractual and managerial practices in project supplier management. Closing the gap is crucial to enable the client organizations to sustain the change in intermittent project environments over time.

\section{Conclusion}

This article has revealed the major challenges that project clients face when applying a relational contracting strategy to new infrastructure development. It has also uncovered key dos and don'ts that managers want to be aware of so as to overcome the challenges. A caveat is in order, though. The challenges are interrelated in ways that, while not discussed here at length, require managerial attention. For example, failure to set the incentives right can make it hard to encourage cooperative work, and it can dissuade competent managers from accepting, or volunteering for, a job in a relational environment. Likewise, failure to create a sense of competition between the suppliers can drive them to relax performance, a problem that can compound if the job matters less for their reputation or if they lack the right skills. Managers who anticipate the interactions will be even better positioned to overcome the challenges.

The bottom line is: A relational contracting strategy is a sensible choice to encourage client-supplier cooperation in large-scale infrastructure projects. However, managers do want to watch how they implement the strategy. Lawyers say that contracts don't deliver projects, but drive behaviors. This seems to be right, by and large, but how exactly the commercial details are spelled out, as well as how they are managed throughout the project, also drive behaviors.

\section{Notes}

1. This effort has been accompanied by a scholarly movement termed "Lean Construction." For seminal works, see L. Koskela, Application of the New Production Philosophy to Construction, CIFE Technical Report 72, Stanford University, 1992; I.D. Tommelein, "Pull-Driven Scheduling for Pipe-Spool Installation: Simulation of Lean Construction Technique," ASCE, Journal of Construction Engineering and Management, 124/4 (1998): 279-288.

2. See I. Macneil, "Relational Contract Theory as Sociology: A Reply to Professors Lindbenberg and De Vos," Journal of Institutional and Theoretical Economics, 143 (1987): 272-290. For classic works on the concept of a contract as a flexible framework for yielding rules, involving open-ended, vague provisions (of dubious legal enforceability), see K.N. Llewellyn, “What Price Contract? An Essay in Perspective," Yale Law Journal, 40 (1931): 704-751.

3. For a condensed and edited summary of Macneil's work, see I. Macneil, edited by David Campbell, The Relational Theory of Contract: Selected Works of Ian Macneil (London: Sweet \& Maxwell, 2001). This work and this reflection refer to contracts involving written forms, but the term "relational contracts" has also been used to refer to informal agreements sustained by the value of future relationships. See, for example, G. Baker, R. Gibbons, and K.J. Murphy, "Relational Contracts and the Theory of the Firm," The Quarterly Journal of Economics, 117/1 (February 2002): 39-84. 
4. See, for example, O. Williamson, The Economic Institutions of Capitalism. (New York, NY: Free Press 1985); K. Monteverde and D. Teece, “Appropriable Rents and Quasi-Vertical Integration," Journal of Law and Economics, 25/2 (October 1982): 321-328.

5. See, for example, R. Gulati, "Does Familiarity Breed Trust? The Implications of Repeated Ties for Contractual Choice in Alliances," Academy of Management Journal, 38/1 (February 1995): 85-112; M. Granovetter, "Economic Action and Social Structure: The Problem of Embeddedness," American Journal of Sociology, 91 (1985): 481-510; S. Maccaulay, "Non-Contractual Relations in Business: A Preliminary Study," American Sociological Review, 28 (1963): 55-69.

6. See, for example, J.P. Womack, D.T. Jones, and D. Roos, The Machine that Changed the World (New York, NY: Harper Perennial, 1990); J.K. Liker, R.R. Kamath, S.N. Wasti, and M. Nagamachi, "Supplier Involvement in Automotive Component Design: Are There Really Large U.S. Japan Differences?" Research Policy, 25/1 (January 1996): 59-89.

7. Williamson, op. cit.

8. For an analysis of the fragmentation of these supply chains, see E. Cacciatori and M.G. Jacobides, "The Dynamic Limits of Specialization: Vertical Integration Reconsidered," Organization Studies, 26/12 (2005): 1851-1883.

9. A.L. Stinchcombe and C.A. Heimer, Organization Theory and Project Management (Oslo: Norwegian University Press, 1985).

10. S.R. Clegg, T.S. Pitsis, T. Rura-Polley, and M. Marosszeky, “Governmentality Matters: Designing an Alliance Culture of Inter-Organizational Collaboration for Managing Projects," Organization Studies, 23/3 (2002): 317-337.

11. For a thorough discussion, see M. Bensaou, "Portfolios of Buyer-Supplier Relationships," Sloan Management Review, 40/4 (Summer 1999): 35-44.

12. See K.J. Mayer and N.S. Argyres, "Learning to Contract: Evidence from the Personal Computer Industry," Organization Science, 15/4 (July/August 2004): 394-410; N. Argyres and K.J. Mayer, "Contract Design as a Firm Capability: An Integration of Learning and Transaction Cost Perspectives," Academy of Management Review, 32/4 (2007): 1060-1077.

13. For a discussion on researching through case study designs involving multiple units of analysis (embedded designs), see R.K. Yin, Case Study Research: Design and Methods, Applied Social Research Methods Series, $3^{\text {rd }}$ Edition (Thousand Oaks, CA: Sage Publications, 2003). For a discussion how single-setting research can help to "see new theoretical relationships and question old ones," see W.G. Dyer and A.L. Wilkins, "Better Stories and Better Constructs: The Case for Rigour and Comparative Logic," Academy of Management Review, 16/3 (1991): 613-619.

14. For a discussion on the ever-changing nature of large-scale projects, see A. Stinchcombe, Delays and Project Administration in the North Sea, Rapport nr. 14, The Institute of Industrial Economics, Bergen, Norway, 1979.

15. See N. Gil, "On the Value of Project Safeguards: Embedding Real Options in Complex Products and Systems," Research Policy, 36/7 (2007): 980-999; N. Gil, S. Beckman, and I. Tommelein, "Upstream Problem-Solving under Uncertainty and Ambiguity: Evidence from Airport Expansion Projects," IEEE Transactions on Engineering Management, 55/3 (2008): 508522.

16. I.R. Macneil, "Barriers to the Idea of Relational Contracts," in F. Nicklish, ed., The Complex Long-Term Contract (Heidelberg: C.F. Muller Juristischer Verlag, 1987), pp. 31-44.

17. L. Poppo and T. Zenger, "Do Formal Contracts and Relational Governance Function as Substitutes or Complements?" Strategic Management Journal, 23/8 (August 2002): 707-725.

18. Stinchcombe and Heimer, op. cit. For making communications authoritative, see also C.I. Barnard, "Function and Pathology of Status Systems in Formal Organizations," in William F. Whyte, ed., Industry and Society (London: McGraw-Hill, 1946), pp. 46-83.

19. See I.R. Macneil, The New Social Contract: An Inquiry into Modern Contractual Relations (New Haven, CT: Yale University Press, 1980).

20. See I.R. Macneil, "Contracts: Adjustments of Long-Term Economic Relations under Classical, Neoclassical, and Relational Contract Law," Northwestern University Law Review, 72 (1978): 854-905.

21. M. Sako, Prices, Quality and Trust: Inter-Firm Relations in Britain and Japan (Cambridge: Cambridge University Press, 1992).

22. Clegg et al., op. cit.

23. Treated by Williamson [op. cit.] as forms of "trilateral governance."

24. Williamson, op. cit. 
25. See T. Knott, No Business as Usual: An Extraordinary North Sea Result, The British Petroleum Company, plc, 1996.

26. Sir John Egan was the CEO of BAA from 1990 to 1999 after a career in the automotive industry.

27. For early comparative studies, see S. Helper, "How Much Has Really Changed between U.S. Auto-Makers and Their Suppliers?" Sloan Management Review, 32 (1991): 127-143; Liker et al., op. cit.; J.K. Liker and Yen-Chun Wu, “Japanese Automakers, U.S. Suppliers, and Supply-Chain Superiority," Sloan Management Review, 42/1 (Fall 2000): 81-93.

28. Jim Ross, "Introduction to Project Alliancing," Proceedings of the Alliance Contracting Conference, Sydney, Australia, 2003.

29. Conversations where the agenda, processes, and outcome were unclear. See K.E. Weick, The Social Psychology of Organising, $2^{\text {nd }}$ edition (Reading, MA: Addison-Wesley, 1979).

30. See T.S. Pitsis, S.R. Clegg, M. Marosszeky, and T. Rura-Polley, "Constructing the Olympic Dream: A Future Perfect Strategy of Project Management," Organization Science, 14/5 (September/October 2003): 574-590.

31. See N.M. Post, "A New Process Paradigm," Engineering News-Record, November 26, 2007. Other related initiatives include the new forms of contract issued by the American Institute of Architects (A201-2007) and by a consortium of independent groups (ConsensusDOCS).

32. For more on the Toyota Production system, see Womack et al. op. cit.; M. Sako, "The Role of Trust in Japanese Buyer-Supplier Relationships," Ricerche Economiche, 45 (1991): 2-3; J.H. Dyer and K. Nobeoka, "Creating and Managing a High-Performance Knowledge-Sharing Network: The Toyota Case," Strategic Management Journal, 21/3 (2000): 345-367.

33. Womack et al., op. cit., p.155.

34. For a thorough discussion on the capabilities of system integrators, see A. Davies, T. Brady, and M. Hobday, "Charting a Path Toward Integrated Solutions," Sloan Management Review, 47/3 (Spring 2006): 39-48; Andrew Davies, David Gann, and Tony Douglas, "Innovation in Megaprojects: Systems Integration at London Heathrow Terminal 5," California Management Review, 51/2 (Winter 2009) [this issue].

35. Dyer and Nobeoka, op. cit.

36. Dyer and Nobeoka, op. cit.

37. For research at the basis of ProjectFlow, see G. Ballard, The Last Planner System of Production Control, doctoral dissertation, School of Civil Engineering, The University of Birmingham, UK, 2000; H.J. Choo, I.D. Tommelein, G. Ballard, and T.R. Zabelle, "WorkPlan: ConstraintBased Database for Work Package Scheduling," Journal of Construction Engineering and Management, 125/3 (1999): 151-160.

38. R.G. Cooper, "Stage-Gate Systems: A New Tool for Managing New Products," Business Horizons, 33/3 (May/June 1990): 44-54.

39. See J. Dyer, “Does Governance Matter? Keiretsu Alliances and Asset Specificity as Sources of Japanese Competitive Advantage," Organization Science, 7/6 (November/December 1996): 649-666; A. Saxenian, Regional Advantage (Cambridge, MA: Harvard University Press, 1994).

40. Gulati, op. cit.

41. Dyer and Nobeoka, op. cit.

42. The same director would argue in 2007 that "BAA could have saved at least £0.5billion" had it implemented the T5 agreement in a different way.

43. "Business: Up, Up and Away," The Economist, July 24, 2004.

44. Sharer observed a similar reluctance to accommodate change with defense contractors even when they were also reimbursed for the costs. See F.M. Scherer, The Weapons Acquisition Process: Economic Incentives (Boston, MA: Division of Research, Harvard Business School, 1964).

45. Pitsis et al., op. cit.

46. Mayer and Argyres, op. cit.

47. The loci of contract design capabilities are dispersed among engineers, managers, and lawyers. For work on how organizations need to align the knowledge of the different groups (with respect to various types of contract terms) with the writing of the different types of contractual provisions, see Argyres and Mayer, op. cit.

48. R. Miller and D. Lessard, The Strategic Management of Large Engineering Projects (Cambridge, MA: MIT Press, 2000).

49. See S.J. Carson, A. Madhok, and T. Wu, “Uncertainty, Opportunism, and Governance: The Effects of Volatility and Ambiguity on Formal and Relational Contracting," Academy of Management Journal, 49/5 (2006): 1058-1077. 
50. Stinchcombe goes further in noting that control in reimbursable contracts is also needed to prevent individuals from practicing corruption in procurement, time sheet, and payment activities. Stinchcombe and Heimer (1985), op. cit.

51. J. Richardson, "Parallel Sourcing and Supplier Performance in the Japanese Automobile Industry," Strategic Management Journal, 14/5 (July 1993): 339-350.

52. Williamson, op. cit.

53. See J.H. Dyer, D.S. Cho, and W. Chu, "Strategic Supplier Segmentation: The Next 'Best Practice' in Supply Chain Management," California Management Review, 40/2 (Winter 1998): 57-77; Sako, op. cit.; Bensaou, op. cit; A. Kaufman, C.H. Wood, and G. Theyel, "Collaboration and Technology Linkages: A Strategic Supplier Typology," Strategic Management Journal, 21/6 (June 2000): 649-663.

54. In the face of flights cancelled, bags going astray, and huge queues building up, the British press called it "the T5 opening fiasco," a discussion outside the scope of this reflection. 
Copyright of California Management Review is the property of California Management Review and its content may not be copied or emailed to multiple sites or posted to a listserv without the copyright holder's express written permission. However, users may print, download, or email articles for individual use. 